\title{
Gestos mínimos y pedagogía de las diferencias
}

\author{
Anelice Ribetto
}

UERJ/FFP, Niteroi, Rio de Janeiro, Brasil. Email: anelatina@gmail.com

Resumen: ${ }^{1}$ Este ensayo se presenta como un ejercicio de pensamiento sobre gestos, palabras e imágenes como políticas y poéticas en el campo de la pedagogía de las diferencias. Así, como introducción, presenta algunas inquietudes de este campo de estudio, inquietudes movilizadas por la propia tensión entre el discurso jurídico y la pasión ética desplegada como efectos de los acontecimientos cotidianos en la alteridad. Después de esta apertura tensa, el texto presenta el concepto de gestualidad mínima a través de cuatro posibilidades expresivas de cuatro gestos pedagógicos: la imagen, la narrativa y la poética (percepción) del gesto. Un gesto. Un gesto mínimo. Un acontecimiento que irrumpe y provoca experiencia en el campo educativo: su presencia, viene antes; antes de cualquier reforma en las leyes, de cualquier propuesta didáctica, de cualquier adaptación de la currícula, de cualquier proyecto político pedagógico. El gesto antecede estos movimientos: es una composición y un pasaje entre todos ellos.

Palabras clave: gesto mínimo, diferencias, alteridad.

\section{Minimal gestures and pedagogy of differences}

\begin{abstract}
This essay opens like a possibility to talk about gestures, words and images as politics and poetics in the area of pedagogics of differences. Thus, as an entry, it presents some questions of this field of study, moved by the very tension between juridical discourse and the ethic passion unfolded as effects of everyday events on otherness. After this tense opening I present intensely the concept of minimal gestures through four expressive possibilities of four pedagogical gestures: the image, the narrative and the poetic (perception) of the gesture. A gesture. A minimal gesture. An event that irrupts and provokes experience in the educational field: its presence comes before; before any reform of the laws, of any didactic proposition, any curricula adaptation, any political-pedagogical project. The gesture precedes these movements: its a composition and a passageway between all of them.
\end{abstract}

Key words: minimal gesture, differences, otherness.

\section{Gestos mínimos e pedagogia das diferentas}

Resumo: Este ensaio se apresenta como um exercício de pensamento sobre gestos, palavras e imagens como políticas e poéticas no campo da pedagogia das diferenças. Assim, como abertura, apresenta algumas inquietações deste campo de estudos, inquietações mobilizadas pela própria tensão entre o discurso jurídico e a paixão ética aberta como efeitos dos acontecimentos cotidianos na alteridade. Após uma abertura tensa, o texto apresenta o conceito de gestualidade mínima através de quatro possibilidades expressivas de quatro gestos pedagógicos: a imagem a narra- 
tiva, a poética e a percepção do gesto. Um gesto. Um gesto mínimo. Um acontecimento que irrompe e provoca experiência no campo educativo: sua presença vem antes; antes de qualquer mudança nas leis, de qualquer proposta didática, de qualquer adaptação curricular, de qualquer projeto político- pedagógico. O gesto antecede estes movimentos: é uma composição e uma passagem entre todos eles.

Palabras chave: gesto mínimo, diferenças, alteridade

$* * *$

Trabajo en el campo de lo que hoy podríamos llamar "pedagogía de las diferencias” desde 1993, cuando joven psicóloga graduada en la Universidad Nacional de Córdoba, me fue ofrecido mi primer empleo en el área. El espacio: una escuela especial. En toda mi formación de graduación no había tenido ninguna disciplina que abordase, estudiase, entrase en este campo. Que yo recuerde, no había tenido experiencias significativas con personas con deficiencias... para mí se presentaba como un espacio desconocido -aún hoy se presenta así...-

Cuando entré a la escuela, en el primer día de clase, fui recibida por un alumno sordo. Entiendo este encuentro como un gesto casi fundante de lo que, años después, entendería como políticas de alteridad... en la escuela. Claudio me abordó y empezó a hablar valiéndose de gestos espontáneos. Encarándome verborrágicamente con el cuerpo. Mi primer movimiento, el gesto urgente que hice fue el de girar la cabeza fingiendo que no lo veía. De esta manera retire el sujeto del campo comunicativo que, no sólo con su presencia, sino con su existencia, me enfrentaba a lo desconocido, al acontecimiento... ¿Qué tipo de relación pedagógica podría crearse a partir de la aniquilación comunicativa -física y simbólica- del otro?

Veinte años pasaron y puedo decir que toda mi experiencia como investigadora en el campo se inspira -política y poéticamente- en este primer gesto: mi tesis de maestría "De las diferencias y otros demonios. El realismo mágico de la alteridad en la Educación” y mi tesis de doctorado "Experimentar la investigación en Educación y Ensayar su Escritura”, producidas en la UFF. Los trabajos, proyectos y deseos de investigación en la Facultad de Formación de Profesores de la UERJ... Mis escritos, mis lecturas son efectos de ese y otros, gestos. Mínimos.

Actualmente, coordino un proyecto que estudia la tensión entre el discurso jurídico-legal de las políticas de inclusión contemporáneas destinadas a los alumnos con deficiencias y la pasión ética que, como efecto, se materializa en el cotidiano escolar de las escuelas. Y allí, otro gesto me ha llamado, sistemáticamente, la atención. Dando clases de la disciplina Educación Especial entro a la sala, en el primer o segundo día de clases, mis alumnos, que están formándose para ser profesores, rápida y repetidamente reproducen un gesto discursivo que vengo enfrentando hace veinte años. Dicen (desde lo alto de una certeza): "profesora, el problema es que los profesores no están preparados para recibir esos alumnos... nosotros no estamos preparados para eso". Ahora bien, ellos, que todavía no son 
profesores, supuestamente “se están preparando”. Como diría Skliar (2010:12) “habría que revisar cuál es la pregunta de la inclusión para la que la respuesta en la escuela común sea, casi siempre, "no estamos preparados” para educar ese niño, ese joven”

El gesto discursivo como efecto de una política de formación que tematiza, caracteriza, sistematiza aquello que fue considerado como anormal, sin enfrentar la necesidad de deconstruir la idea de normalidad que atraviesa la propia política de formación de profesores. El gesto discursivo como efecto de una política de formación que entiende en la “posesión” de los instrumentos técnicos previos la certeza del dominio ético de la posibilidad del encuentro pedagógico. Y allí, “¿cómo desdecir aquella idea de que para estar juntos habría que, primero, preparar la bienvenida al otro con todos los detalles, conocerlo con anticipación, regular su llegada y luego, después, más tarde, sólo más tarde, sentirnos responsables y desear la relación?” (Ibid, 2009:8)

Vengo pensando -junto a algunos autores como el propio Carlos y Nuria Pérez de Lara, entre otros- por lo menos dos posibilidades en la dirección de analizar esa pregunta. Son ellas: la primera, cuestionar la certeza de que para encontrarme con alguien -cualquier persona- tengo que saber todo de él de antemano, y confundir algunas características del sujeto con el sujeto mismo: por ejemplo, confundir la sordera con Claudio, mi alumno sordo; confundir el autismo, con Manuel, un alumno que voy a presentar más adelante, etc. Esto sólo es posible, deconstruyendo una formación que apunta a entender la "anormalidad" sin tocar la idea de "norma" como se ella fuese "natural”: ¿por qué tematizar a los alumnos ciegos y no estudiar el por qué de una pedagogía centrada sólo en quien ve con los ojos? ¿Por qué tematizar a los deficientes mentales y no problematizar una pedagogía evolucionista y psicologicista que divide en etapas la experiencia de aprender? Centrar la pregunta pedagógica en la relación, en aquello que nos pasa en el momento del encuentro con “cualquiera”, como dice Skliar.

La segunda posibilidad es cuestionar el mandato social histórico de que los profesores y las escuelas tendríamos, en pos de la "educación para todos”, que hacer grandes peripecias y hazañas políticas y pedagógicas. Cuestionar el mandato de la educación salvadora y de los profesores héroes para apostar en la potencia mínima de los gestos de convivencia. Convivencia entendida como pura tensión, puro conflicto, pura negociación de deseos, como diría Eduardo Coutinho.

Gesto como efecto posible del encuentro...

Gesto como efecto político y poético del encuentro con el otro... Con cualquier otro...

Les presentaré, entonces, el concepto de “gestualidad mínima” como agenciamiento que me permite pensar el educar como una relación de alteridad posible. 
Este concepto me llegó durante mi investigación de doctorado en 2007. Yo deseaba entender la risa como un saber -indecible-que irrumpe, desmoraliza la oficialidad de la escuela y llegué -por desplazamiento conceptual-al concepto de "saber menor"2. En mi examen de proyecto, Carlos Skliar, me regaló el concepto de “gesto mínimo” que actualmente es potente en la investigación, especialmente porque cuando estudio la tensión entre los discursos políticos y el cotidiano escolar necesito diferenciarme del campo de investigación que se reduce a una comparación entre los dos agenciamientos y entender los efectos que se crean a partir de esta tensión: prácticas, experiencias, currículos, espacios, tempos... Gestos encarnados en las relaciones entre los sujetos que viven las escuelas posibles... Gestualidad mínima que interpela "sobre el lenguaje en que formulamos lo educativo (...) sobre los modos en que se produce lo educativo (...) abriendo la posibilidad hacia una cierta forma de pensar sobre "eso que pasa", “eso que nos pasa” en la educación a diario” (Ibid, 2011:260)

Entonces, van cuatro gestos. Gestos que me acompañan hace por lo menos diez, quince años. Gestos que dan visibilidad mínima, apenas perceptible, al encuentro pedagógico que llega e irrumpe a partir del acontecimiento. Y produce experiencia.

Voy a presentarlos de esta manera: la imagen del gesto... La narrativa del gesto... La poética (percepción) del gesto...

\section{Primer gesto... “esa flauta está tapada... ¿por qué en él?”}

La imagen del gesto... ${ }^{3}$

La narrativa del gesto.

1998. Provincia de Córdoba, Argentina. Sala de Psicología de la Escuela Jerónimo Luis de Cabrera, Argentina. La cámara encima de una mesa está tomando mi encuentro con Claudio. Claudio es un alumno de 15 años que asiste clases en nuestra escuela desde pequeño. Dos de sus hermanos terminaron la escolaridad primaria en la "escuela común” nocturna, después de haber estudiado durante años en la "escuela especial”. Ellos fueron algunos de los primeros integrados a final de los años ochenta.

Claudio tiene sordera. Además de muchas otras cosas, es sordo. No conocemos las razones por las que le "restó” una audición de 10\% comparada a un oyente medio. No tiene diagnóstico preciso, tal vez, una otitis mal curada. No usa aparatos. No aprendió la Lengua Argentina de Señales entre otras razones, porque no se le posibilitaron recursos económicos suficientes para viajar 200 kms. Claudio creo una lengua con gestos espontáneos que, para mí que tuve el placer y el privilegio de relacionarme con él, marcaría e inauguraría un proceso de aprendizaje angustiante, apasionante.

Allí estamos Claudio y yo, sentados en frente de la mesa, tentando 
descifrar una partitura musical que él estaba aprendiendo a tocar en la flauta. Claudio sigue las notas con su dedo en una escritura que para mí es indescifrable y percibe que "se equivocó” una nota: desafinó. Esta era una situación que habitualmente lo frustraba mucho. Entonces, de nuevo la cámara capta la posibilidad de existencia de otras lógicas para explicar lo que estaba sucediendo.

\section{Primero, yo repito numerosas veces}

- "Escúchame Claudio, escúchame” y percibo en seguida que él no me mira hasta que este "escúchame" sin sentido va acompañado de gestos y manos que lo tocan... así sí el escúchame pasa a tener otro sentido.

\section{ironía:}

\section{Claudio mira mi cara al desafinar e inmediatamente me comunica con}

- "No soy yo... no es mi soplido incontenible... es esa flauta que no es capaz de sonar bien con otros soplidos como el mío... parece que ella tiene algún defecto dentro... parece que está tapada.”

Las palabras le surgen de las manos, del rostro, de los ojos, del cuerpo...

Me pregunto si sólo siendo (in)diferente no entendería lo que él me estaba diciendo. Entender su habla, no significa que entonces su manera de hablar vaya a instaurarse como un nuevo dogma, como única verdad, como oración de iglesia, pero, ¿por qué no verla como otra versión posible de lo que estaba ocurriendo?

Jorge Larrosa hablando de Nietzsche \& Educación plantea esa cuestión sobre el reconocimiento de las verdades o lógicas de los otros. Digamos que yo no puedo encontrar en alguien más de lo que espero encontrar, ni saber más de lo que ya sé. Entonces, por ejemplo, si tengo la vivencia de "no escuchar nada” me puede producir "la ilusión acústica de creer que, donde nada se escucha, tampoco nada existe” (Larrosa, 2004:18).

La irrupción inaudita de las “palabras” de él y mi propio espanto ante mi percepción de que su "reconocimiento como otro que sabe” empezó cuando conseguí pensar que la lengua en la que estábamos hospedados tenía una "condición babélica, multiplicidad de lenguas en la propia lengua” (Ibid, 2004:70) y que cualquier explicación o interpretación que intentase hacer sobre sus palabras sería sólo una "traducción del sentido” (Ibid: 77). En este momento, fue posible - sin planear que así fuese - la emergencia del acontecimiento “de lo que llega y por consiguiente de lo que, porque llega del otro, en él es previsible” (Derridá, 1997:8) Al cuestionar la mismidad de la única posibilidad de que su soplido fuese equivocado, que sólo pudiese escuchar la música a través de los oídos o comunicarse sólo a través de la palabra dicha, Claudio me ayuda a pensar en que aquello que en 
el otro continua siendo misterio, aquello del otro que no sé y no controlo, aquello insoportable de asumir como potencia en la mayoría de las pedagogías es lo que aún permite el encuentro en las diferencias y la posibilidad de discutir la alteridad en la educación: “Podría ser esto, pero, también podría no ser sólo esto. Ser otra cosa que yo no sé qué es”. ${ }^{4}$

Pensando en esto me acuerdo del texto "Dar a leer... tal vez”, donde Jorge Larrosa plantea una referencia que me parece fundamental cuando hablamos, escribimos, leemos, en fin, tejemos nuestros conocimientos en el cotidiano, y en las relaciones de alteridad. Algunas de las cosas que hablamos, escribimos, escuchamos, leemos son lo que él llama "expresiones demasiado legibles” (Larrosa, 2004:16), yo las llamaría también demasiado decibles, demasiado escribibles, demasiado escuchables; "sabemos de antemano lo que significan (...) como hacer para que la lectura [yo diría la escritura y el diálogo] vayan más allá de esta comprensión problemática, demasiado tranquila, en la que sólo leemos [escribimos, escuchamos y decimos] lo que ya sabemos leer” [escribir, escuchar y decir] (Ibid, 2004:16).

La percepción- la poética del gesto...

De Natalia Litvinova, “Los ciegos”, citado por Carlos Skliar (2001:107): "los ciegos de mi ciudad no dormían a la noche, trazaban coordenadas, marcaban sus caminos con piedras. De mañana los campesinos tropezaban con las mismas piedras y furiosos se deshacían de ellas. ¿Quién atenta contra nuestro orden?, preguntaban. Lo mismo se preguntaban los ciegos.”

\section{Segundo gesto... Ver... con las manos...}

La imagen del gesto...

La narrativa del gesto.

1998. Provincia de Córdoba, Argentina. Sala de Psicología de la Escuela Jerónimo Luis de Cabrera, Argentina. La cámara que comprara con lo que junté de los salarios do mi primer año de trabajo en la escuela está encima de una silla. En la alfombra, esforzándose para encontrar una posición que contenga sus movimientos continuos está Manuel, 14 años, alumno regular de la escuela especial. Manuel fue diagnosticado como persona con "síndrome de Williams" . Junto a él, estoy yo. No recuerdo bien cuál era el objetivo que este encuentro con él tenía, pero me acuerdo que yo disfrutaba estando con él. Tal vez sea por esto que está registrado en el video. Me empiezo a preguntar sobre los lugares corporales de los sentidos y sus funciones, no es un diálogo de esos diálogos entendidos como "un conflicto entre individuos que hablan en el mismo plano, en el mismo universo ideológico, en el mismo lenguaje” (Larrosa, 2000:178) Es otra cosa. En un dado momento, yo pregunto

- “Manu, ¿para qué sirven los oídos?” 
- “Manu, ¿con qué me ves?”

Él me da un montón de respuestas. "Desorganizadas, caóticas, sin sentido, incoherentes”... termino sin saber si responde o no responde o qué responde. Revienta mis certezas: "Los oídos sirven para escuchar, pero, las personas escuchan con los oídos", "Las personas vemos a través de los ojos”. Pasan unos minutos y él me dice:

- “Manos. Manos... con las manos...Ane... escuchá, Ane... escuchá... escuchá" - y en un sólo movimiento va su voz con sus manos que, a cada lado de mi rosto, me dicen "¡escuchá!”.

Termina nuestro encuentro. Manuel sólo lleva con él mi reconocimiento de las "incoherencias entre los lugares del cuerpo, los sentidos y sentires" como una característica ya esperable y previsible a partir del diagnóstico do que "él era". No tenía mucha cosa a esperar. Manu, o mejor, la narrativa legitimada sobre él creada por el discurso de poder-saber circulante en la escuela, ya sabía lo que él era y aquello que de él podríamos esperar. Mas, aún en el "discurso de pureza y normalidad” existen también “corporificaciones de la suciedad”, como diría Bauman (1998:17) refiriéndose a aquellos seres humanos que funcionan como piedra en el camino del orden homogeneizador, como obstáculo para la "apropiada organización do ambiente" Fue en la "suciedad de la relación" donde nos fue posible aprender alguna cosa, resistir, crear.

Diez años después vi el video del encuentro con Manu y la sorpresa irrumpió. ¿Cómo no había percibido? ¿Cómo podía no ver ni escuchar lo que él estaba diciéndome como otra manera de respuesta a mi pregunta?

¿Por qué razones la lógica de mis respuestas tendrían una superioridad a la lógica de las respuestas de él?

Es en el necesario reconocimiento de que fuimos instruidos para hacer del otro lo mismo, a través del enaltecimiento de una lógica, un saber, una lectura, (una etnia, un sexo, un color, una forma de amar, morir, vestir, comer, hablar, producir, etc.) y, evitando el enfrentamiento con los propios demonios que intentó exorcizar la modernidad, que podremos iniciar a cuestionar nuestro invento más desolador: la creencia de que, a través del conocimiento denominado científico, el hombre podrá llenar la angustia de su finitud. Me pregunto, ¿cómo se garantizaría esa "producción de creyentes”? Larrosa dice: "A los libros predicadores corresponden lectores creyentes” (:24) (...) [Este tipo de lector, profesor o alumno] "Ignora los enigmas porque sólo sabe hacer a si mismo preguntas a las cuales pueda anticipar la respuesta” (2004:44)

La percepción y la poética del gesto...

De Margarite Yourcenar, citada por Carlos Skliar (2011:112): “Diverso. Nada me parece más dulce que aquellos momentos de inmovilidad, sen- 
tada o tirada junto a los seres diversamente amados - o igualmente amados - durante los cuales no nos vemos uno al otro, sino contemplamos las mismas cosas y el cuerpo permanece (...) con la ilusión de no ser, por el momento, más que dos miradas acordes”.

\section{Tercer gesto... "la escritura babélica y ahí está todo dicho”}

\section{La narrativa del gesto.}

Escribí mi tesis de maestría en portuñol -entre portugués y en español. Un texto escrito en español, en el espacio donde estudié funcionó de alguna manera como alteridad lingüística. El gesto: mi tesis se abre en la pantalla de la computadora de cada uno de mis compañeros y la mayoría de ellos comenta la sorpresa y la primera sensación de extrañamiento que esto provoca: João Baptista, mi profesor, me ayuda con su metáfora cuando expresa "cuando yo vi que el texto de la Ane estaba en español, me congelé”, inmediatamente me acordé de los acontecimientos que me ocurrieron cuando vine a vivir a Brasil. Mi suegro, don Alfredo, era un nordestino del sertão bahiano de 89 años que migró para el sudeste en precarias condiciones. Él podría ser un extranjero en su propia lengua, y esa característica constituye "una diferencia política, no simplemente una diferencia formal, textual o lingüística” (Skliar, 2001:98). Don Alfredo me ayudó a pensar en la multiplicidad que nos forma y en las diferentes lógicas con las que los seres humanos pueden ser y pensar el mundo. Don Alfredo no sólo hablaba portugués: hablaba portugués de Brasil, y hablaba con todo el acento del sertão bahiano. Él vivió más de cuarenta años en Belford Roxo, Baixada Fluminense, periferia carioca. Yo creo que encarnaba aquella "condición babélica de la lengua” a la que Larrosa (2004:57) se refiere cuando plantea la traducción como algo inherente a la condición humana y a cualquier forma de relación inter-subjetiva: "la condición babélica de la lengua no significa solamente la diferencia entre las lenguas, sino la irrupción de la multiplicidad de la lengua en la lengua, en cualquier lengua” (Ibid:70) Antes de conocernos me moría de curiosidad acerca de la forma en que íbamos a comunicarnos, ya que yo estaba balbuceando, con acento de Córdoba, las primeras frases en portuñol. Mi compañero lo llamó por teléfono, sacando el tema para conversación, le preguntó-desafió sobre cómo pensaba que íbamos a entendernos cuando nos encontrásemos. Don Alfredo respondió: -“Oxe [oxente] muchacho, que crees... eso no es problema... uno se encuentra y ahí no más, nos damos la mano... ahí está todo dicho... uno ya sabe cómo es... no tiene que decir más nada”-

“Ahí está todo dicho”, “ahí”, “ahí”... me repito aún. ¿Dónde queda este “ahí”? ¿En cuál parte del gesto? ¿En el darse las manos? ¿En el calor de las manos? ¿En la textura de las manos? ¿En el espacio vacío y lleno entre las manos?

Mi madre vino a visitarme a Río por primera vez. Por causa de una serie de acontecimientos, ella pasó las dos semanas recorriendo los hospi- 
tales cariocas en lugar de tomar sol en Ipanema. En las dos semanas que estuvo en Brasil no aprendió una palabra en portugués. Cuando alguien hablaba con ella, desesperadamente buscaba la ayuda de un "intérprete" En el momento de volver para Argentina, estábamos en la fila del check-in cuando una funcionaria de Aerolíneas Argentinas le dijo, mirándola, en perfecto y amable español le dijo: “- Señora, por favor, usted tiene que llenar la ficha de migraciones”. Ella, con cara de espanto, se dio vuelta buscando los ojos de un traductor. La miré, sin poder creer lo que estaba viendo, entonces, ella me dijo “- Ane... no entiendo qué me está diciendo... ¿¿qué me dijo?”

Creo que esto es, de alguna manera, algo de lo que pasa cuando las personas que "naturalmente" habitamos "una misma" lengua que es nuestra y es propia, que nos constituye como sujetos, nos deparamos con el deber de comprender otra lengua, mas, comprender con nuestra, propia y misma lógica, y no la del otro; comprender para "convertir lo distante en próximo, lo extraño en familiar, lo otro en lo mismo" (Larrosa, 2004:74). No dispuestos a perder el propio dominio de la situación y sentirnos un poco, por lo menos algunas horas, extranjeros, exilados. Perder la mismidad y sentir en la carne que “...la traducibilidad, a veces, es la aproximación a la muerte de dos lenguas, la original y su copia. Si se ha de considerar el texto original como un cadáver de otro tiempo, entonces su traducción será el cadáver de este tiempo. Por eso, duele la traducción y duele el original” (Skliar, 2004:129).

No-saber, ignorancia, falta de explicación para comprender qué significa esa frase, [silencios], no tener dominio de las teorías citadas, perder el hilo ante la falta de una escritura sistematizada, no decir algunas cosas que deben decirse, el texto tiene lagunas, exposición, incerteza, me congelé, artesanía discursiva, traducción, laberinto, sombras y luces, extranjero que habita en nosotros, y otras...

Cuando me pienso como sujeto de la educación - investigadora y pesquisada - y cuando me planteo como sujeto que se enfrenta - guste o no - con esa "irreductibilidad infinita del otro" (Derridá, 1997:1) la pregunta que detona es, ¿cómo pensar ese acogimiento del otro en la educación? Un acogimiento que no se pretenda libre de los demonios y fantasmas de la alteridad pero que reivindique la solidaridad como posibilidad paradigmática de relación.

La percepción y la poética del gesto...

Acoger al otro en su lengua es tener en cuenta naturalmente su idioma, en el pedirle que renuncie a su lengua y a todo lo que ésta encarna, es decir, unas normas, una cultura (lo que se denomina una cultura), unas costumbres, etc. La lengua es un cuerpo, en él se le puede pedir que renuncie a eso... Se trata de una tradición, de una memoria, de nombres propios. Evidentemente, también resulta difícil pedirle hoy en día a un Estado-nación que renuncie a exigirles a 
aquellos a los que acoge que aprendan su lengua, su cultura en cierto modo (p.6) (...) Por consiguiente, tanto en el terreno político como en el terreno de la traducción poética o filosófica, el acontecimiento que hay que inventar es un acontecimiento de traducción. En el de traducción en la homogeneidad unívoca, sino en el encuentro de idiomas que se aceptan sin renunciar en la mayor medida posible a su singularidad (DERRIDA, 1997, 2001:7)

\section{Cuarto gesto... soplidos sordos... el gesto mínimo de Gloria... ${ }^{7}$} oyentes.

Gloria es profesora de música “preparada” para enseñar a alumnos

Gloria se encuentra por primera vez con cuatro adolescentes sordos y piensa que tal vez sea posible tocar la flauta... junto a los cuatro adolescentes sordos. Pero este movimiento exige el aprendizaje o la sensibilidad para "afinar" el instrumento... Gloria aprendió que un instrumento se afina "por el oído”. Gloria...

El oído "no funciona” para esa afinación aprendida por la profesora

La profesora y los cuatro adolescentes crean otra forma de percepción de la afinación. Gloria agarra su encendedor y lo prende frente al alumno... el alumno sopla y en la intensidad del balancearse de la llama por el aire del soplido, en el gesto de balancearse, en la sinfonía entre la fuerza del soplido y la luz de la llama, se encuentra la “afinación”.

La percepción y la poética del gesto.

Un gesto. Un gesto mínimo. Un soplido.

Implicarse en este acontecimiento posibilita entrever en el espacio de la mismidad - representado por la generalidad discursiva Escuela- "la mirada que no juzga, ni condena previamente, la mirada para posibilitar otras existencias diferentes de la nuestra, que saluda, que pregunta, permite, posibilita, deja hacer, sugiere, conversación” (Skliar, 2009: medio digital)

Un gesto. Un gesto mínimo. Un acontecimiento que irrumpe y provoca experiencia. El gesto, su presencia, viene antes... antes de cualquier reforma en las leyes, de cualquier propuesta didáctica, de cualquier adaptación de la currícula, de cualquier proyecto político pedagógico. El gesto antecede estos movimientos: es una composición y un pasaje entre todos ellos. 


\section{Notas}

${ }^{1}$ Traducción: Silvina Julia Fernández.

${ }^{2}$ Desplazamiento producido en la lectura de Deleuze y Guatarri (1977) Kafka: por una literatura menor. Imago, Rio de Janeiro.

3 Ver: http://www.youtube.con/watch?v=MC4Aoc8buA0\&list=UU3LrdtBIPa0 Noam915mBtPw\&index $=6$

${ }^{4}$ Inspirada en palabras de Carlos Skliar.

${ }^{5}$ Ver: http://www.youtube.con/watch?v=GBDDJEirOto\&list=UU3LrdtBIPa0Noam91 $5 \mathrm{mBtPw} \&$ index $=2$

6 "El síndrome de Williams es un esporádico accidente genético que remueve una importante región del cromosoma 7, eliminando cerca de 30 genes. Algunos de estos genes actúan en conjunto y son responsables por problemas cognitivos, mientras que otros puedan causar problemas morfológicos, como defectos en el corazón. Pacientes con ese síndrome presentan dificultades de orientación espacial y cálculos numéricos. Pero lo que realmente llama la atención es el fenotipo social, una pasión por compañía y diálogo, junto con una mala interpretación de la dinámica social y total falta de inhibición en un ambiente extraño. De esta forma, a los portadores de Williams les encanta la conversación, conversación sobre todo y con cualquier persona, sin el menor miedo social” En: http://www.swbrasil.org.br/artigos/teoria-de la-mente

${ }^{7}$ Ver: http://www.youtube.con/watch?v=_OmxxQhB2D0\&list=UU3LrdtBIPa0No am915mBtPw\&index $=7$ 


\section{Bibliografía}

Bauman, Z. (1998), O Mal-estar da Pós-Modernidade. Jorge Zahar Editor, Rio de Janeiro.

Derridá, J. (1994), “”Desconstruir la actualidad. Passages, № 57, 11/1993, pp. 60- 75); Revista El Ojo Mocho. Revista de Crítica Cultural, Buenos Aires, 5, Primavera 1994.

Idem. (1997), “Sobre la hospitalidad”. (Entrevista en Staccato, programa televisivo de France Culturel producido por Antoine Spire, del 19 de diciembre de 1997); Revista ¡Palabra!, Trotta, 2001, pp. 49-56 (Traducción al español: Cristina de Peretti y Francisco Vidarte);

Larrosa, J. (2000), “Elogio do riso”. En: Larrosa, J. Pedagogia profana. Danças, piruetas y mascaradas. Editora Autêntica.Belo Horizonte.

Idem (2004), Lenguaje y educación después de Babel. Editora Autêntica, Belo Horizonte.

Idem (2004), Nietzsche y la educación. Editora Autêntica, Belo Horizonte.

Ribetto, A. (2011), De las diferencias y otros demonios. El realismo mágico de la alteridad en la educación. Ed. Ponto de la Cultura, Maricá.

Skliar, C. (2009) De la crisis de la convivencia y el estar juntos en educación. En: http://www.raco.cat/index.php/REIRE (22/8/2013).

Idem (2011), “De la razón jurídica hacia una ética peculiar. A propósito del informe mundial sobre el derecho a la educación de personas con discapacidad”, Política y Sociedad, Vol. 47 Num. 1: 153-164.

Idem (2004), Intimidad y alteridad. Experiencias con la palabra. Inédito. Mimeo (Publicado en português: Skliar, Carlos. (2012) Experiências com a palavra. Notas sobre linguagem e diferência. Ed. Wak, Rio de Janeiro)

Idem (2011), Lo dicho, lo escrito, lo ignorado. Ensayos mínimos entre educación, filosofía y literatura. Ed. Miño y Dávila, Buenos Aires.

Idem, Medio digital. En: http://www.scielo.org.ar/pdf/orisoc/v8/v8a02.pdf

Idem (2001), “Perspectivas políticas y pedagógicas de la educación bilingüe para sordos”. En: Silva, S. y Vizim, M. (orgs.) Educación especial: múltiples lecturas y diferentes significados. ALB y Mercado de las Letras, Campinas, SP. 